Michał Nikodem

UnIWERSYTET ŚlLASKI W KaTOWICACH

\title{
Silent Hill jako propozycja realizacji cech gatunkowych konwencji horroru w grach komputerowych - studium komparatystyczne
}

\begin{abstract}
Żyjemy $w$ wieku potwornym, na świecie potwornym, sami potworami bęac. Zło $w$ niemożliwie wysokim natężeniu rozrasta się wszędzie [...] Wszędzie, wzdłuż, wszerz, wzwyż, trójwymiarowe zło $w$ nieskończonej liczbie postaci.
\end{abstract}

Stanisława Przybyszewska ${ }^{1}$

W niniejszym opracowaniu chciałbym przedstawić rozwój i realizację konwencji horroru, tak aby wychodząc od gatunku literackiego, poprzez gatunek filmowy, przejść do horroru jako gatunku gier komputerowych.

Według Słownika terminów literackich pod redakcją Janusza Sławińskiego:

Horror (ang. przerażenie, dreszcz) - jedna z odmian literatury fantastycznej, mająca także swój odpowiednik filmowy; operuje motywami, których zadaniem jest budzenie u czytelnika silnych reakcji emocjonalnych, przede wszystkim właśnie - przerażenia. Do tradycyjnych motywów wykorzystywanych w horrorach należą: straszace duchy, wampiry, wędrówki po starych, na ogół zrujnowanych zamkach i podziemiach. Horror ukształtował się w XVIII w. w powieści gotyckiej i w powieści grozy. Bliskie mu były niektóre utwory reprezentujace frenezję romantyczna (m.in. E. A. Poe), a współcześnie stał się jedną $z$ form kultury popularnej (m.in. filmy A. Hitchcocka, powieści S. Kinga) ${ }^{2}$.

Ta krótka definicja $z$ pewnością oddaje istotne cechy horroru jako gatunku literackiego. Można byłoby ją jednak uzupełnić

1 S. Przybyszewska, Listy, t. 1: Grudzień 1913 - wrzesień 1929, Gdańsk 1978, s. 113.

2 M. Głowiński, Horror, [w:] Słownik terminów literackich, red. J. Sławiński, Wrocław 2000, s. 202. 
o pewien rys historyczny, wskazując na ciagłość opowieści wzbudzających groze w kulturze ludzkiej. Jedna $z$ najstarszych prac wspominajacych o dziwnych istotach jest sanskrycki tekst Dwadzieścia pięć opowieści Wampira ${ }^{3}$. Ten zbiór, który dotrwał do naszych czasów świadczy o tym, że potrzeba bycia straszonym, przeżywania strachu $\mathrm{w}$ kontrolowanych warunkach - i przez to oswajania go - były (i sa) jednym ze stale towarzyszących nam aspektów ludzkiej twórczości. Jeżeli chodzi o czasy nam bliższe, to mówi się, że Johann W. Goethe był jednym z prekursorów gatunku horroru w Europie - w utworze pt. Narzeczona z Koryntu (wydrukowanym w 1798 r.) wprowadził motywy grozy, towarzyszące pierwszemu pojawieniu się wampira na kartach literatury wyso$k^{1} j^{4}$. Bardzo ważna dla przeszłości horroru jest także wspomniana przez Michała Głowińskiego w Słowniku terminów literackich tradycja powieści gotyckiej i powieści grozy. Zamczysko $w$ Otranto Horacego Walpole'a (1764), Tajemnice zamku Udolpho (1794) Ann Radcliffe czy Mnich Matthew Lewisa (1796) reprezentuja tę tradycje (Mnich może być określony również mianem utworu frenetycznego). W XIX w. pojawiają się tak klasyczne i znane powszechnie utwory, jak Frankenstein (1818) Mary Shelley, opowieści Edgara Allana Poego (publikowane od 1832 do 1849 r.), Niezwykły przypadek Doktora Jekylla i Pana Hyde'a (1886) Roberta Louisa Stevensona czy Drakula (1897) Brama Stokera. Szczególnie te XIX-wieczne realizacje gatunku określiły rodzące się wówczas nowoczesne, masowe wyobrażenia o tym, co straszne i zagrażające. Powieści te otoczone były aura tajemniczości, często pojawiał się w nich nieznany nikomu bohater, który $\mathrm{w}$ trakcie opowieści konstruował swoja tożsamość. Interesujący sposób prowadzenia narracji proponuja Opowieści niesamowite E. A. Poego, w których pozycja narratora niejednokrotnie jest niejasna, sprzeczna, powikłana, przez co czy-

${ }^{3}$ Dwadzieścia pięć opowieści Wampira, przeł. i oprac. H. Willman-Grabowska, Wrocław 1955. Nie jestem pewny, czy pojęcie wampira jest tutaj na miejscu - powinni to określić biegli wampirolodzy. Istotą opowiadająca owe opowieści jest w tym cyklu bóg Śiwa, który przemawia poprzez ciało zmarłego. Wydaje się więc, że bliżej temu zjawisku do istoty określanej mianem zombie, choć nie znam przypadku literackiego, w którym zombie byłoby opętane i kontrolowane przez boga. Kwestia określenia tej istoty pozostaje więc otwarta, z pewnością w sprecyzowaniu tożsamości tego zjawiska pomocna może być książka M. Janion, Wampir. Biografia symboliczna, Gdańsk 2008.

${ }_{4}$ Postać wampira, upiora, w taki czy inny sposób nieumarłego, funkcjonowała w folklorze, również i w naszym, słowiańskim, kręgu kulturowym, o czym pisze Maria Janion w swojej książce Niesamowita Słowiańszczyzna. Zob. M. Janion, Niesamowita Słowiańszczyzna. Fantazmaty literatury, Kraków 2007. 
telnik nie może ufać jego słowom (jak np. w opowiadaniu Berenice). Opowieści E. A. Poego zaludniał tłum bohaterów $z$ marginesu życia: opiumistów, chorych psychicznie, somnambulików. Taki układ sił dowartościowywał zwykłego człowieka, jednocześnie zaspokajając jego potrzebę poznania odmiennego sposobu widzenia świata poprzez opisy innych, różnych od normalnych, stanów psychicznych.

$Z$ punktu widzenia psychologii można się zastanawiać, czy wzrost zainteresowania horrorem u progu nowoczesności był związany ze zwiększaniem się poczucia bezpieczeństwa i komfortu życia członków społeczeństw, czy też odwrotnie - czytelnicy chcieli odnaleźć w tekstach odbicie własnego niepokoju wobec wzrastajacych wymagań i życia przyspieszającego tempo. Zapewne odpowiedź jest złożona - pozostawmy jej sformułowanie socjologii lektury. Nas interesować będzie szczególnie jeden aspekt zjawiska, o którym wspomniałem, a mianowicie zwiększająca się wśród czytelników chęć obcowania $z$ dziełami frenetycznymi, wypełnionymi groza, niesamowitymi stworzeniami i zjawiskami. Niewątpliwie część tej fascynacji można przypisać specyficznemu romantycznemu duchowi epoki, czego świadectwem jest w polskiej literaturze twórczość mistyczna Juliusza Słowackiego, szczególnie Król Duch (dzieło niedokończone, pisane w latach 1845-1849), w którym dochodzi do eksplozji okrucieństwa i grozy, a wszystko to w imię pobudzenia ducha dziejów do ingerencji w losy państwa polskiego.

Wracając jednak do głównego wątku naszych rozważań, należy zauważyć, że upowszechnienie tego gatunku stało się faktem, a rozwijajace się od czasów wynalazku braci Lumière kino przejęło to zainteresowanie i wykorzystało je do własnych celów. Badacze kina (tacy jak autorzy pomieszczeni w pierwszym tomie historii kina, zatytułowanym Kino nieme ${ }^{5}$ ), szczególnie w jego początkach, zwracaja uwagę na nowe medium „ruchomych obrazów” jako na sposób, dzięki któremu coraz większa liczba ludzi uzyskiwała dostęp do obiegu kultury, do wymiany idei. Podobnie jak na początku nowożytności wynalazek ruchomej czcionki drukarskiej otworzył nowe możliwości szerzenia poglądów i tworzenia wspólnot myśli (co umożliwiło rozwój języków narodowych i takich ruchów, jak reformacja), tak kino dało dostęp do cudów i dziwów świata (kroniki filmowe), wydarzeń politycznych czy naukowych (widoki geograficzne). Kino miało spełniać również rolę dostarczyciela niezwykłości - tak jak pierwsi operatorzy filmowi zostali wysłani w świat przez Lumière'ów, aby uwiecznić najciekawsze miejsca na Ziemi, dostarczając widzom

5 Kino nieme, red. nauk. T. Lubelski, I. Sowińska, R. Syska, Kraków 2009. 
niezwykłości, tak też film fabularny podążył tą drogą. Eksperymenty Georgesa Mélièsa, jego Podróż na Księżyc z dwukrotnym lądowaniem rakiety (pokazujacy odmienne od współczesnego rozumienie czasu w dziele), stały się podstawą do zapoczątkowania nowego gatunku sztuki filmowej - fantastyki naukowej. Jeżeli kierować się zaproponowana na początku definicja i przyporządkować horror do tego nurtu, wówczas już gdzieś tam dałyby się datować jego początki. Idąc dalej, zwróćmy się w stronę tego, co Bartłomiej Paszylk w swojej ksiażce The Pleasure and Pain of Cult Horror Films ${ }^{6}$ nazywa „The root of all horror". Jest to pierwszy rozdział (opisujacy lata 1921-1935) jego studium, które obejmuje wybrane „kultowe” horrory $z$ lat 1921-2005. Listę tę otwiera Körkarlen (Woźnica śmierci, 1921) w reżyserii szwedzkiego twórcy Victora Sjöströma. Film opowiada historię pijaka Davida Holma, który doświadcza fantastycznej sytuacji wyjścia $z$ ciała ('smierci) w Sylwestra. Jak powiedział jeden $z$ jego kompanów, ten, kto umiera dokładnie o północy, zostaje mrocznym żniwiarzem - woźnica śmierci, odtąd Holm będzie musiał zabierać dusze innych (widzimy tu, jak przestrzeń pomiędzy nowym a starym porządkiem staje się przestrzenią nieokreślona, a przez to niebezpieczną; stąd wszelkie krwawe obrzędy liminalne, majace na celu ustanowienie progu - granicy). Towarzyszac mrocznemu żniwiarzowi, Holm przypomina sobie przeszłe wydarzenia, zło, które wyrządził i niewdzięczność wobec innych. Okazuje się bowiem, że takim zachowaniem doprowadził do desperacji swoja żonę, która wraz $z$ dziećmi próbuje popełnić samobójstwo. Holm, będąc duchem, może jedynie obserwować jej przygotowania. Jest to moment krytyczny, w którym dochodzi do przemiany bohatera. Wtedy także budzi się on, żywy, na płycie nagrobnej i w ostatniej chwili ratuje swoją żonę. Film kończy się modlitwą do Boga z prośba o wybaczenie.

Tę opowieść, w której konwencja horroru i grozy jest wykorzystana do stworzenia moralitetu, cechuje kilka znaczacych elementów. Przede wszystkim postać bohatera jako tego, który jest człowiekiem ułomnym, $\mathrm{z}$ marginesu, dotkniętym alkoholizmem, nasuwa skojarzenia $z$ równie „marginalnymi” bohaterami E. A. Poego. Tam jednak nie wiedzieliśmy, co jest prawda, tu natomiast, poprzez rozgraniczenie porządków (ciało - duch, dobro - zło, życie - śmierć) otrzymujemy dokładnie określona, dualistyczna przestrzeń, w jakiej rozgrywa się dramat. Groza jest tutaj nośnikiem

${ }^{6}$ B. Paszylk, The Pleasure and Pain of Cult Horror Films. An Historical Survey, Jefferson 2009. 
pewnych treści moralnych, pełni funkcję podobna do katharsis, tak jak jest ona opisana w Poetyce Arystotelesa ${ }^{7}$, a więc jako przeżycie uczuć litości i trwogi, które uwalnia od tych uczuć poprzez umożliwienie ich przeżycia w bezpiecznym otoczeniu. Skojarzenia $z$ talking cure i psychoanalitycznym uwalnianiem się od symptomu poprzez jego wypowiedzenie również sa tu na miejscu. Można powiedzieć, że groza służy tutaj do pobudzenia bohatera do refleksji nad własnym postępowaniem, staje się czynnikiem motywującym do zmiany. Czy natomiast czynnik ten musi być aż tak groźny? Rozważając tę kwestię $z$ psychologicznego punktu widzenia, można skorzystać z propozycji Jamesa Hillmana (ucznia Carla Gustava Junga, który w krytyczny sposób przetworzył jego idee). Mówi on o tym, że wszystko, co przeżywa psyche, może stać się impulsem do przemiany, a szczególnie moga to być sytuacje trudne (stąd tytuł jego książki: Samobójstwo a przemiana psychiczna ${ }^{8}$. Groza i fantastyczne zjawiska, jakie przeżywa w Wózku widmie $e^{9}$ Holm, sa skoncentrowane na uświadomieniu mu jego błędów, co, jak widzimy $\mathrm{w}$ ostatniej scenie, przynosi zamierzony efekt - przemianę moralna głównego bohatera.

Mówiliśmy o tym, że upowszechnienie kina pozwoliło na dostęp do kultury szerszym warstwom społeczeństwa. Tak jak kino było kamieniem milowym na drodze rozwoju sposobów przekazywania idei i wywoływania emocji, tak też upowszechnienie komputera osobistego (personal computer, PC) oraz wykorzystanie go jako platformy multimedialnej i rozrywkowej pozwoliło na przesunięcie kolejnych barier dostępności. Oczywiście największą rewolucją była rewolucja internetowa, tutaj jednak zaakcentujmy aspekt indywidualnej i osobistej rozrywki, nie będziemy więc mówili o $\mathrm{MMO}^{10}$. Doświadczanie grozy w obcowaniu $z$ ksiażka było indywidualne, natomiast doświadczanie grozy w kinie jest zbiorowe. Oczywiście, każdy przeżywa emocjonujące sytuacje w głębi własnej duszy, jednak zawsze w bliskim sasiedztwie znajduje się inny, samotny widz (przypomina się tutaj Leibnizowskie pojęcie monady - byłyby więc to monady kinowe). Kolektywne oglądanie horrorów ma jednak swoje wady:

\footnotetext{
7 Arystoteles, Poetyka, przeł. i oprac. H. Podbielski, Warszawa 1983.

8 J. Hillman, Samobójstwo a przemiana psychiczna, przeł. D. Rogalski, Warszawa 1996.

9 Jest to inna wersja polskiego tłumaczenia tytułu oryginału.

${ }_{10}$ MMO lub MMOG to akronim angielskiej nazwy massively multiplayer online game, oznaczajacej gry rozgrywane przez Internet, w które zaangażowanych jest wielu graczy $z$ różnych stron świata, korzystających $z$ różnych platform sprzętowych.
} 
jeżeli ktoś krzyknie, wtedy trudno nie poczuć dreszczu na karku; gdy ktoś głośno komentuje, trudno nie czuć agresji (bardziej na komentatora niż $z$ powodu filmu), a jeżeli siorbie coca-colę i chrupie popcorn, to często całkiem niszczy specyficzny kontakt pomiędzy widzem a obrazem filmowym. Nie zapominajmy tutaj również o ciemności, która jest bardzo ważnym elementem fenomenologii odbioru obrazu kinowego, często wykorzystywanym w realizacjach filmowych, oczywiście także w horrorach. Tak wiec medium kinowe, jak każdy środek przekazu, miało i ma swoje mankamenty. Rozrywka w zaciszu przestrzeni domowej usuwa obecność innych widzów, co diametralnie zmienia sytuację odbioru (mówimy tu także o odbiorze dzieła filmowego poprzez medium, jakim jest kino domowe) ${ }^{11}$. Wprowadzając dodatkowo pewien element decyzyjności i sprawstwa (jak w grach komputerowych), otrzymujemy wysoki stopień zaangażowania uczestnika przy jednoczesnym znaczacym stopniu izolacji od świata. Wydaje się, że sa to idealne warunki do tworzenia światów fantastycznych, w tym takich jak świat horroru.

W tym miejscu chciałbym skoncentrować się na odmianie gatunkowej horroru w grach komputerowych, jaka jest survival horror. W tej odmianie głównym celem nie jest eliminacja budzacych grozę przeciwników (co czyni się najczęściej po to, aby oczyścić świat od zła). Tu świat jest zły ze swej natury, demonicznych sił nie da się wyplenić, co powoduje konieczność życia w przestrzeni zdefektowanej, naznaczonej błędami i cierpieniem. Przypomina się gnostycka koncepcja świata i złego demiurga. Chodzi więc nie tyle o to, żeby zabijać, lecz o to, żeby samemu nie zostać zabitym; nie tyle o dominację, ile o przetrwanie. Do reprezentacyjnych przykładów tego gatunku zaliczyć można serie: Resident Evill ${ }^{12}$ oraz Silent Hill (oczy-

11 Jednocześnie wprowadza w znana przestrzeń domową element niesamowitości i grozy, element niedomowy (Unheimlich), o którym pisał Z. Freud w artykule Niesamowite (Das Unheimliche), analizujac dzieła literackie. Zob. Z. Freud, Niesamowite, [w:] tenże, Pisma psychologiczne, przeł. R. Reszke, Warszawa 1997, s. 235-262.

12 Jej czwarta część (Resident Evil 4) jest według serwisu internetowego GameRankings (zbierającego oceny $z$ recenzji zamieszczonych w najważniejszych magazynach poświęconych grom komputerowym) najlepsza gra na platformę PlayStation 2, z wynikiem 95,77\% (GameRankings - Video Game Reviews from around the Internet [online]; www.gamerankings.com [data dostępu: 23.06.2013]). Natomiast według serwisu Metacritic, prezentującego wyniki poszczególnych gier na podstawie ocen krytyków, Resident Evil 4 znajduje się na trzecim miejscu $z$ wynikiem 96 (na 100) punktów. Wyprzedzaja go tylko tytuly: Tony Hawk's Pro Skater 3 oraz Grand Theft Auto III, obydwa z wynikiem 97 pkt (Metacritic-Movie Reviews, TV Reviews, Game Reviews and Music Reviews; www.metacritic.com [data dostępu: 23.06.2013]). 
wiście tytuły sa tu znaczace: Zamieszkałe zło i Ciche Wzgórze). Tutaj chciałbym zając się drugim $z$ wymienionych cyklów. Tytułowe wzgórze bynajmniej nie jest zielone, choć to kurort wypoczynkowy, obecnie zamieszkany przez wszelkiej maści istoty z piekła rodem. W dziwny sposób do miasta przybywaja głównie osoby posiadające jakiś defekt, te, które popełniły zbrodnię lub nie rozliczyły się ze swoja przeszłością, co sugeruje, że groza może pełnić tu funkcje podobne do „oczyszczającej” i „umoralniającej” funkcji grozy, o jakiej wspomnieliśmy przy analizie Wózka widmo V. Sjöströma. Niektórzy interpretatorzy przyjmuja, że miasteczko Silent Hill jest czymś w rodzaju czyśćca. Bohaterowie kolejnych części serii musza przejść przez poszczególne próby po to, aby (być może) doświadczyć zbawienia. Musiałoby to być jednak zbawienie bez boga, ponieważ swiat Cichego Wzgórza jest mroczny, otoczony wiecznymi ciemnościami lub też nieprzenikniona mgła; to świat nieprzejrzysty, który bogowie dawno opuścili lub też istnieja jeszcze w postaci demonów, co nie niesie pocieszenia. $\mathrm{W}$ grach tego typu świat jest tajemnica do rozwiazania, na każdym kroku stawiajacym przed graczem kolejne pytania. Na niektóre $z$ nich znajdujemy odpowiedzi, co rozwija akcję, większość tajemnic pozostaje jednak nierozwikłana, niekiedy też znajdujemy odpowiedzi bez pytań, co otwiera przestrzeń do kolejnych spekulacji.

Za najlepszą część w cyklu Silent Hill gracze uznają albo druga, albo pierwsza, założycielską cześć serii ${ }^{13}$, w której pojawiły się nieodłaczne atrybuty serii - latarka i radio. Latarka pozwala rozświetlić mroki tego miejsca, często jest też jedynym źródłem światła (oczywiście dopóki baterie się nie rozładuja), a radyjko tranzystorowe trzeszczy, ostrzegając przed zbliżającymi się potworami. Te dwa elementy, podobnie jak mgła i ciemność, stały się cechami rozpoznawczymi serii, budując specyficzny klimat cyklu. Należą do nich również arcytrudne zagadki - ponieważ osobno ustalamy poziom trudności zagadek i walki ${ }^{14}$, przy ustawieniu obu na maksimum doprowadzamy do tego, że „biegamy od jednej arcytrudnej zagadki do drugiej, po drodze roztrącając cherlawe potwory”, jak przeczytałem kiedyś w jednej z recenzji gry Silent Hill 2.

13 Pierwsza część ukazała się w 1999 r. na platformę PlayStation, druga w 2001 r. na PlayStation 2, podobnie trzecia w 2003 r. We wspomnianych wcześniej serwisach punktacja wygląda następująco (wyniki poszczególnych części w kolejności chronologicznej): GameRankings - 84,99\%, 85,77\%, 83,77\%; Metacritic - 86 pkt, 89 pkt, 85 pkt [data dostępu: 23.06.2013].

14 Możliwość taka otrzymujemy od drugiej części serii, w pierwszej mamy możliwość ustalenia tylko jednego poziomu trudności. 
W drugiej części cyklu, którą uważam za bardziej interesująca, wcześniejsze pomysły zostały rozwinięte $z$ zachowaniem konwencji. Bohaterem jest w niej James Sunderland, mężczyzna w średnim wieku, który trafia do Silent Hill w poszukiwaniu swojej zmarłej żony - Marii. Skłania go do tego jej list, w którym żona zaprasza go do odwiedzenia kurortu, będącego ich wspólnym „szczególnym miejscem". Miasto oferuje w ten sposób bohaterowi swoista lekcję, można powiedzieć lekcję moralna, $z$ której skorzystać moga także gracze. Od ich wyborów zależy rozwój historii i wyjaśnienie głównego watku, a także dalsze losy Sunderlanda. Silent Hill nie daje prostych odpowiedzi - w mieście pojawiaja się poszlaki w postaci pozostawionych książek, gazet, notatek, co $z$ jednej strony może pomóc w wyjaśnieniu zagadki, a $z$ drugiej jeszcze bardziej komplikuje sprawę. Element frenetyczny, o którym mówiliśmy przy analizie horroru jako gatunku literackiego, objawia się w ekspansji potworów różnej maści. Niektóre $z$ nich sa olbrzymie, inne małe, jeszcze innych w ogóle nie widać. Wszystkie one strasza czy wręcz przerażaja, a ich kształt, miejsce występowania czy rodzaj odgłosów, jakie wydają, mówi coś o świecie, w jakim się poruszamy i o psychice głównego bohatera, w którą uzyskujemy wgląd. Jest to kompozycja otwarta - sami decydujemy o losach bohatera, a sposób rozstrzygnięcia stawianych przed nami zadań wpływa na kształt świata.

Tak jak rozpoczęliśmy nasza pracę cytatem z Listów Stanisławy Przybyszewskiej, tak też teraz, zmierzając do końca, przyjrzymy mu się bliżej, przytaczając słowa skierowane do Antoniego Słonimskiego, napisane w Gdańsku 10 września 1927 r.:

Żyjemy w wieku potwornym, na świecie potwornym, sami potworami będąc. Zło w niemożliwie wysokim natężeniu rozrasta się wszędzie - w szkolnictwie i w systemie dyktatury, w polityce celnej i w polityce Kościoła, w sądownictwie i w zwiąkach zawodowych, w Genewie, w Mandżurii, w Paryżu, na Sumatrze. Wszędzie, wzdłuż, wszerz, wzwyż trójwymiarowe zło w nieskończonej liczbie postaci. Uciec przed nim nie można - panuje we wszystkich ugrupowaniach ludzkości, we wszystkich gałęziach ludzkiego zajęcia i dążności. Otacza każdy umysł sferyczną, nieprzenikniona ściana. Więc pozostaje nam albo patrzeć spokojnie - i zidiocieć, bo widok nad siły; albo walczyć. Skupić cała treść życia w sile ciosu ${ }^{15}$.

S. Przybyszewska diagnozuje w tym fragmencie stan Europy i świata ze świadomościa zła jako nieodłącznego elementu nowoczesnych dziejów ${ }^{16}$, przejawiającego się nie tylko w postaci wojen,

15 S. Przybyszewska, dz. cyt., s. 113.

16 List ten był pisany w 1927 r., a więc w dziewięć lat po zakończeniu I wojny światowej i dwanaście lat przed wybuchem II wojny światowej. 
lecz także będącego elementem codziennego funkcjonowania porządków państwowych i instytucjonalnych. W wizji autorki nie ma miejsca na ucieczkę, każda jednostka postawiona jest w sytuacji wyboru, bierność prowadzi do „zidiocenia” "17; jedynym wyjściem jest walka ze złem, wykorzystująca całą siłę życiowa jako broń w tej potyczce. Przy wszystkich zastrzeżeniach, jakie mógłby budzić ten krok $^{18}$, wydaje się, że ten opis daje się zastosować do charakterystyki świata gry Silent Hill ${ }^{19}$.

Ludzi z Cichego Wzgórza, dotkniętych jakimś defektem, ułomnościa $z$ powodu zbrodni, jakie popełnili, można nazwać potwora$\mathrm{mi}^{20}$. Co więcej, same potwory w grze mogły być kiedyś ludźmi ${ }^{21}$ - w części drugiej ostatnim przeciwnikiem, z którym walczy gracz, jest Maria-potwór (widzimy ją oczami Jamesa); w części trzeciej ostatnim wrogiem jest bóg zrodzony $z$ człowieka, natomiast według niektórych interpretacji sprawczynią całego zła w miasteczku jest Alessa Gillespie ${ }^{22}$, opętana przez starożytnego boga-demona, który zmienia jej naturę; jest przyczyna klątwy, istnienia potworów i wiecznych ciemności. Tak jak w świecie opisywanym przez S. Przybyszewska, zło w Cichym Wzgórzu jest nieuniknione, nie da się oczyścić miasta, zbyt dużo było w jego historii okrucieństw i cierpienia. Jedynym wyjściem jest skupienie całej swojej witalności i przekształcenie jej w wolę przetrwania, w wolę walki. Co więcej, nie można liczyć na zbawienie czy odkupienie, a całkowita eliminacja zła jest niemożliwa - zło zamieszkałe w mieście zawsze będzie się odradzać. Jak pisze S. Przybyszewska:

17 Bierne przyglądanie się złu niszczy patrzącego - jak w horrorach H. P. Lovecrafta, samo spojrzenie na złe istoty mogło spowodować obłęd. Ciekawa analizę pisarstwa H. P. Lovecrafta przedstawia w swojej książce M. Houellebecq (M. Houellebecq, H. P. Lovecraft. Przeciw światu, przeciw życiu, przeł. J. Giszczak, Warszawa 2007).

18 Należy pamiętać przede wszystkim o tym, że S. Przybyszewska opisywała świat realny, tak jak on się jej jawił, my natomiast stosujemy te kategorie do opisu świata wyobrażonego, jakim jest świat gry komputerowej.

19 Być może sama S. Przybyszewska z zainteresowaniem przyjęłaby tę interpretację, będąc wielka miłośniczką rozpowszechnionego już wówczas medium, jakim było kino wraz z kolejnymi, klasycznymi już dzisiaj, realizacjami filmowymi.

20 Sunderland zabił swoja nieuleczalnie chora żonę, co było jednym $z$ jego grzechów głównych, odkrywanych przez gracza. Od działań „detektywistycznych” i decyzji graczy zależy, jak będzie przedstawiona motywacja tego czynu (od miłosierdzia po chęć pozbycia się zbędnego ciężaru) oraz dalsze losy bohatera (wybaczenie mu przez Marię i opuszczenie Silent Hill, początek nowego życia, samobójstwo).

${ }^{21}$ Moga też stanowić personifikację grzechów głównych bohaterów.

22 Sprawczynia może też być jej matka, Dahlia Gillespie, która odprawiła mroczny rytual przywołujący boga. 
Nie ma przed nami nic finalnego, bezwarunkowego, żadnego szczytu; nie ma tego „bliskiego dnia” odczuwanego jako spełnienie - wieczność; jest tylko bezpośrednie jutro. Tak krótkie, tak ciężkie, tak powszednie - jak dziś. I pracujemy dla tego powszedniego jutra w tej tylko nadziei, że uda nam się oszczędzić mu części zła dzisiejszego. Że wśród bezliku zmór, które nas dziś zjadają, uda nam się zabić kilka. Kilka - wiedząc w dodatku, że miejsce tych kilku zajmie kilka świeżych. Mizerne to słońce, skąpe źródło sił! ${ }^{33}$

W Silent Hill jedyna dostępna wieczność to wieczny powrót tego samego zła - cierpienia, potworów i ciemności, których nie da się usunać.

Uważam, że możemy potraktować Silent Hill jako kolejny etap na drodze rozwoju gatunku, jakim jest horror. Wychodzac od literackich źródeł horroru, wskazaliśmy na jego zakorzenienie w ludzkiej psychice, w sposobach odczuwania i przeżywania strachu. Sposoby te sa uwarunkowane biologicznie, ale kształtowane kulturowo, przez co ich formy ulegały zmianie na przestrzeni wieków. Kiedyś były to przede wszystkim książki, późnej filmy, teraz forpocztą nowej wrażliwości jest gra komputerowa i gra ta niesie ze soba współczesne sposoby przeżywania lęków i problemów.

\section{Bibliografia}

Arystoteles, Poetyka, przeł. i oprac. Henryk Podbielski, Warszawa 1983.

Dwadzieścia pięć opowieści Wampira, przeł. i oprac. Helena Willman-Grabowska, Wrocław 1955.

Freud Z., Pisma psychologiczne, przeł. R. Reszke, Warszawa 1997.

GameRankings - Video Game Reviews from around the Internet [online]; www.gamerankings.com [data dostępu: 23.06.2013].

Hillman J., Samobójstwo a przemiana psychiczna, przeł. D. Rogalski, Warszawa 1996.

Houellebecq M., H. P. Lovecraft. Przeciw światu, przeciw życiu, przeł. Jacek Giszczak, Warszawa 2007.

Janion M., Niesamowita Słowiańszczyzna. Fantazmaty literatury, Kraków 2007.

Janion M., Wampir. Biografia symboliczna, Gdańsk 2008.

Kino nieme, red. nauk. T. Lubelski, I. Sowińska, R. Syska, Kraków 2009.

Metacritic - Movie Reviews, TV Reviews, Game Reviews, and Music Reviews; www.metacritic.com [data dostępu: 23.06.2013].

Paszylk B., The Pleasure and Pain of Cult Horror Films. An Historical Survey, Jefferson 2009.

Przybyszewska S., Listy, t.1: Grudzień 1913 - wrzesień 1929, Gdańsk 1978.

Słownik terminów literackich, red. J. Sławiński, Wrocław 2000.

${ }^{23}$ S. Przybyszewska, dz. cyt., s. 114. 


\title{
Filmografia
}

Podróż na Księżyc, reż. G. Méliès, 1902.

Woźnica śmierci (Wózek widmo), reż. V. Sjöström, 1921.

\begin{abstract}
Article shows horror as polimedial genre. Analyze begins from literature definition of this genre, few historical realizations presents important literature works which shows characteristic elements of that medium. Closer look on famous horror films, which are analyzed in next paragraph, are concentrating on important characteristics of this genre in field of "moving pictures". The last part of this article shows how main parts of this genre are realizing in that new part of human entertainment which are computer games, illustrating main idea of all analysis, that horror changes for better illustration of fears which are irremovable part of human condition.
\end{abstract}

Key words: horror, genre, polimediality, movie, computer games. 